\title{
Transplante jurídico Legal trasplant
}

\author{
Christian J. Backenköhler Casajús \\ Universidad Autónoma de Madrid \\ ORCID ID 0000-0001-7776-308X \\ chris.backen@gmail.com
}

Cita recomendada:

Backenköhler Casajús, C. J. (2019). Transplante jurídico. Eunomía. Revista en Cultura de la Legalidad, 17, 262-275.

doi: https://doi.org/10.20318/eunomia.2019.5032

Recibido / received: 30/06/2019

Aceptado / accepted: 06/09/2019

\section{Resumen}

El trasplante jurídico es una metáfora del derecho comparado creada para señalar el traspaso normativo que se produce entre diferentes ordenamientos jurídicos. En un primer momento, el trasplante jurídico sirvió para demostrar que, desde hace tiempo, el traspaso normativo fue un mecanismo frecuentemente utilizado para crear nuevos sistemas jurídicos o para la adaptación o renovación de muchos de ellos. Pero, con el tiempo, se ha ido configurando como un concepto que, aparte de describir el traslado de una norma de un sistema jurídico a otro, trata también de explicar las posibles consecuencias que puede sufrir el ordenamiento jurídico receptor. En la actualidad, el trasplante jurídico está sirviendo para explicar la transferencia normativa entre diferentes ordenamientos jurídicos en el contexto de la globalización y también como indicador de la existencia de un pluralismo jurídico en el espacio jurídico actual.

\section{Palabras clave}

Trasplante jurídico, pluralismo jurídico, derecho comparado, préstamo jurídico, pluralismo cultural.

\begin{abstract}
The legal transplant is a comparative law metaphor created to indicate the normative transfer that occurs between different legal systems. At first, the legal transplant served to demonstrate that, for a long time, the normative transfer was a mechanism frequently used to create new legal systems or, also, for the adaptation or renewal of many of them. Over time, however, it has developed into a concept which, apart from describing the transfer of a rule from one legal system to another, also seeks to explain the possible consequences that the receiving legal system may suffer. At present, legal transplant is serving to explain the normative transfer between different legal systems in the context of globalization and, also, as an indicator of the existence of legal pluralism in the current legal space.
\end{abstract}

\section{Keywords}

Legal trasplant, legal pluralism, comparative law, legal borrowing, cultural pluralism. 
SUMARIO. 1. Introducción: origen y desarrollo del trasplante jurídico.2. Los trasplantes jurídicos: perspectivas y críticas.- 3. Pluralismo jurídico y dimensión étnica de los trasplantes jurídicos.- 4. Conclusiones.

1. Introducción: origen y desarrollo del trasplante jurídico

Los trasplantes jurídicos son un mecanismo metafórico, utilizado originariamente en la disciplina jurídica del derecho comparado para analizar la importación de normas extranjeras a los sistemas jurídicos propios. El término fue acuñado por primera vez en 1974 por Alan Watson, quien lo definiría como «el desplazamiento de una regla jurídica o de un sistema jurídico de un país a otro, o de un grupo de personas a otro» (Watson, 1993, p. 21). Alan Watson, que por entonces era un reputado académico de historia del derecho, y que estudió, sobre todo, los textos jurídicos romanos, obtuvo un inesperado éxito con su primera incursión en la disciplina del derecho comparado. Con esta pequeña obra, de poco más de cien páginas, Watson consiguió popularizar la metáfora de los trasplantes, que entraron a formar parte de la terminología jurídica actual. Tal fue el éxito, que en ediciones posteriores reconocería su sorpresa, pero también trataría de contestar a muchas de las críticas que recibió y que veremos un poco más adelante.

En su momento, la metáfora del trasplante jurídico tuvo un gran éxito académico básicamente por tres razones (Langer, 2004, pp. 29-30): en primer lugar, porque servía para conceptualizar un fenómeno emergente debido al aumento de la circulación de instituciones y reglas entre sistemas normativos por la globalización, lo que ayudó a teorizar sobre nuevas prácticas jurídicas. En segundo lugar, porque el concepto de trasplante albergaba una naturaleza inherentemente comparativa al hacer referencia a un fenómeno por el cual, al igual que ocurre en botánica o en medicina, una idea, regla o institución jurídica se traslada de un lugar a otro, de un cuerpo (jurídico) a otro. Esto permite comparar su aplicabilidad y funcionamiento en la jurisdicción receptora teniendo en cuenta el sistema jurídico de origen, lo que abre todo un abanico de posibilidades al análisis comparativo entre los diferentes sistemas jurídicos y las influencias de las distintas culturas jurídicas entre sí. Por último, en tercer lugar, porque tras el trasplante resultaba jurídicamente relevante tanto el análisis de la adaptación de la norma al nuevo entorno jurídico como su fracaso o rechazo.

La tesis básica de los trasplantes jurídicos de Watson es que, en ese desplazamiento descrito en su definición, muchas normas o conjunto de normas han viajado de un sistema jurídico a otro desde tiempos inmemoriales. Con esta afirmación Watson establecía que, a lo largo de la historia, los diferentes sistemas jurídicos habían tomado prestado normas e instituciones de otros ordenamientos jurídicos anteriores o contemporáneos, para completar o adaptar su derecho a las necesidades del contexto social que debía regir. Esto significaba que la utilización del préstamo jurídico había sido un mecanismo común en la mayoría de los sistemas jurídicos a lo largo del tiempo, y que muchas normas habían acabado siendo trasplantadas a otros sistemas jurídicos cultural e históricamente distintos. Esta tesis difusionista, con la que en la actualidad se podría estar plenamente de acuerdo, resultó ser toda una revolución dogmática contra la percepción que hasta el momento dominaba en la sociología del derecho y que, por entonces, defendía el 
principio de autonomía del derecho, es decir, la vinculación absoluta del derecho con una sociedad o cultura determinadas (Watson, 1993, p. 96). Watson, en cambio, defendía que la mayoría de las innovaciones jurídicas se habían llevado a cabo tomando prestado figuras legales de otros sistemas jurídicos en los que el trasplante jugó un papel fundamental, habiendo sido el préstamo el principal mecanismo para cambio legislativo en la mayoría de los ordenamientos jurídicos.

En la actualidad, la originalidad normativa es realmente escasa, mientras que el préstamo y la imitación han sido los recursos fundamentales en la evolución del derecho (Sacco, 1991a, p. 394). La mayoría de los sistemas jurídicos contemporáneos se han ido configurando y adaptando al contexto social tomando prestadas normas de otros sistemas jurídicos de cuya imitación se ha ido desarrollando una relación de influencia mutua que traspasa las categorías culturales y temporales ${ }^{1}$. A lo largo de la historia del derecho, por tanto, la imitación o el préstamo fueron mecanismos más fáciles de utilizar que el desarrollo jurídico propio, ya que el derecho ha resultado ser un fenómeno que depende más ampliamente de la experiencia humana que de la espontaneidad y ocurrencia de una sociedad y cultura concretas.

Al respecto, el desarrollo de la imitación, préstamo o trasplante entre sistemas jurídicos ha sido un área de estudio crucial en la rama del derecho comparado. Dentro de esta disciplina del derecho, las razones de la recepción jurídica producidas por alguno de estos fenómenos de difusión, así como los efectos que produce en el ordenamiento jurídico receptor o los límites para su aceptación, resultan fundamentales para el estudio de la naturaleza y viabilidad de cualquier institución jurídica. Mucho más si tenemos en cuenta cómo en la actualidad los niveles de interacción e influencia entre los distintos sistemas jurídicos ha aumentado con la globalización. En el derecho comparado, hasta ahora ha sido corriente ubicar los distintos ordenamientos jurídicos en familias o sistemas jurídicos transnacionales, para, a partir de su clasificación, fomentar la comparación y el estudio de las distintas normas e instituciones y su origen social o cultural (Mousourakis, 2010, pp. 90-91). Durante mucho tiempo, los criterios de clasificación han protagonizado los debates entre los iuscomparativistas, lo que también ha terminado por influenciar más tarde la manera de establecer las razones por las cuales se produce el préstamo o el trasplante entre los diferentes sistemas jurídicos. De este modo, entre las principales teorías de clasificación de los sistemas jurídicos destacaron, por un lado, la propuesta de Arminjon, Nolde y Wolff (1950, p. 47 y ss.). Para estos autores existen ciertos núcleos normativos o modelos jurídicos que han sido sistemáticamente imitados o trasplantados, bien directamente a través de acciones de conquista o colonización, o bien mediante su adopción por otros sistemas jurídicos debido a su calidad o prestigio. Por otro lado, para Zweigert y Kotz (1998), en cambio, más que la existencia de un conjunto de normas primigenias, lo que en realidad existe es la coincidencia en una serie de estilos jurídicos que vienen determinados por los antecedentes históricos, por un

\footnotetext{
1 En la tesis de Watson, el desarrollo del concepto de trasplante jurídico fue para justificar los préstamos que la mayoría de sistemas jurídicos actuales han tomado del derecho romano. Como reputado romanista, Watson quería demostrar mediante esta metáfora que la originalidad de los ordenamientos jurídicos era, en general, discutible, puesto que la mayoría de las normas han sido tomadas de ordenamientos jurídicos anteriores. La excepción, en cambio, es la del propio derecho romano, que prácticamente no tomó prestada ninguna norma (Watson, 2001, p. 98). La consecuencia de esta afirmación es doble: por un lado, como comentamos, esta idea contradice la autonomía del derecho y lo transforma en un fenómeno permeable a la influencia de normas o conjunto de normas de otros sistemas jurídicos encargados de ordenar realidades sociales diferentes; y, por otro, que la construcción del derecho le ha sido encomendada históricamente a los técnicos y profesionales, quienes han tomado como referencia el prestigio de otros sistemas jurídicos como el del derecho romano (Merryman, 2008, p. 26).
} 
pensamiento jurídico determinado, una serie de instituciones jurídicas distintivas, una determinada jerarquía de fuentes legales y un trasfondo ideológico particular. Todas estas características habrían dado lugar a una serie de familias jurídicas, muy relacionadas, en mi opinión, con concepciones esencialistas y civilizatorias: románica, germánica, inglesa, islámica, hindú, de extremo oriente, nórdica y socialista (Zweigert \& Kötz, 1998, pp. 68-75). En todo caso, ambos enfoques tratarían de establecer un origen o una fuente común de acceso a fuentes normativas que habrían estado circulando entre sistemas jurídicos diferentes, pero cuya trasposición a los ordenamientos jurídicos propios se habría dado por diferentes motivos, ya sea por la fuerza o el prestigio, o simplemente por una serie de características comunes o la costumbre.

\section{Los trasplantes jurídicos: perspectivas y críticas}

Para abordar la manera en la que una norma o conjunto de normas entra a formar parte de un sistema jurídico mediante el préstamo, la imitación o, lo que más nos interesa, el trasplante jurídico, los distintos académicos del derecho comparado han construido sus teorías básicamente en torno a dos métodos o perspectivas: una estructuralista, que descompone cada sistema jurídico en una serie de modelos jurídicos o formantes legales ${ }^{2}$, y que se corresponden con las normas jurídicas, la doctrina y las decisiones judiciales (Sacco, 1991, p. 22). Y otra funcionalista, que considera al derecho como un sistema cerrado y autorreferencial (Luhmann, 2016, p. 191), cuyo contenido se autorreproduce para construir su propio espacio de operación y reducción de la complejidad social mediante normas e instituciones jurídicas que ayuden a fijar determinadas expectativas normativas de conducta.

La perspectiva estructuralista, en primer lugar, pretende establecer la tesis básica de que cualquier ordenamiento jurídico está atravesado por una serie de elementos o estructuras que le son innatas, o más bien constantes en el tiempo, y que condicionan su diseño y contenido. Así, el derecho es un fenómeno que estaría completamente disociado del poder político (Somma, 2015, p. 156). Esta presunción estructuralista del derecho, no contempla, por tanto, la capacidad del contexto histórico o social en el desarrollo de su contenido, por lo que difícilmente el ordenamiento jurídico podrá ser un reflejo del poder político o económico subyacentes (Watson, 1993, p. 103). Con la teoría de los formantes legales, los iuscomparativistas pretenden desmenuzar el derecho en sus tres variantes y estudiar el grado de disociación entre todos, determinando, de esta manera, la concordancia que existe entre ellos. Es decir, al descomponer el derecho en sus formantes, se puede llegar a analizar la relación entre los mismos y determinar el grado de coherencia que pueda existir en un ordenamiento jurídico particular. Esto, porque no siempre existe plena concordancia entre los distintos formantes, ya que el formante legal puede estar en contraposición con el judicial, o el doctrinal estar en desacuerdo también con cualquiera de ellos. Y es precisamente estos espacios de disociación lo que importa al derecho comparado.

\footnotetext{
2 La teoría de los formantes de Sacco, muy seguida en Italia, se inspira en la fonética cuando determina la frecuencia de resonancia de los sonidos en la cavidad oral durante la pronunciación con el fin de aislar los sonidos e identificar los distintos componentes. Con esta metáfora, Sacco trata también de disociar los diferentes componentes del derecho identificando un formante legal, para identificar las normas legislativas, un formante doctrinal, para referirse a los estudiosos y académicos del derecho, y un formante judicial, que hace referencia a la producción jurisprudencial de los tribunales (Somma, 2015, p. 153 y ss.).
} 
Para lo que nos interesa, según la perspectiva estructuralista, la circulación o difusión de normas entre los distintos sistemas jurídicos se ha dado fundamentalmente acorde a dos factores: la fuerza y el prestigio. Así, mediante la fuerza, y como resultado de la conquista o la colonización, fueron trasplantados ordenamientos jurídicos enteros sobre los territorios sometidos, como en el caso de la expansión soviética o en las colonias francesas de África. Pero, la difusión de un sistema jurídico por medio de la fuerza, no siempre fue una imposición total del sistema jurídico. Muchas veces, como ocurrió en las colonias británicas o las conquistas de algunos reinos islámicos, los ordenamientos jurídicos locales seguían funcionando o pervivían algunas de sus normas bajo lo que se denominó como ley personal. Ahí están los casos paradigmáticos del sistema de millets del imperio turco, la ley personal india en las colonias inglesas del sudeste asiático (Shah, 2005), o las leyes personales de los países árabes bajo influencia británica que luego se convirtieron en sus actuales estatutos personales.

Salvo algunas excepciones, como el constitucionalismo a la fuerza en Iraq y Afganistán tras las ocupaciones estadounidenses (Papagianni, 2005), en la actualidad el principal método de circulación normativa entre los Estados modernos se ha dado a través del prestigio. Pero el prestigio también fue el método principal de desarrollo para la mayoría de los ordenamientos jurídicos actuales. Tal y como defendía Watson (2001, p. 98), el derecho romano fue el sistema jurídico principal de referencia de casi todos los ordenamientos jurídicos de la actualidad. Desde que los juristas de la época medieval fijaran su modelo de referencia en la compilación justinianea, el derecho de todos los países occidentales ha adoptado desde entonces gran parte del desarrollo jurídico llevado a cabo por los juristas romanos, produciéndose un trasplante masivo de la mayoría de sus normas. Existen algunas razones para explicar ese prestigio del derecho romano (Mousourakis, 2010, p. 93). En primer lugar, en la época medieval en la que se empezaron a trasplantar las normas jurídicas romanas, existía una enorme descentralización territorial, por lo que no existía un sistema jurídico lo suficientemente fuerte para frenar estos préstamos o para imponer sus propias normas. Se daba también la circunstancia, en segundo lugar, de que la mayor parte de los territorios sobre los que se iba a trasplantar esas normas habían formado parte del Imperio romano con anterioridad, por lo que estaban más familiarizados con la estructura jurídica del derecho romano. Y, por último, y ya con la emergencia del Estado-nación, porque los nuevos ordenamientos jurídicos occidentales quisieron codificar sus normas con respecto al modelo romano, con el deseo de emular su sistema jurídico. En cualquier caso, la adopción de las normas de derecho romano no se produjo tanto por la admiración que pudieran provocar en los juristas posteriores, ni siquiera por la adecuación y familiaridad de sus normas para muchos de los territorios y contextos donde se adoptaron. La principal razón fue, en definitiva, la percepción del derecho romano como un sistema y como un importante denominador común en la tradición jurídica occidental.

Hoy en día la circulación normativa obedece ya a otras razones en las que el prestigio o la fuerza ya no son las causas determinantes. Pero lo fueron en su momento y lo han sido en la configuración histórica de la mayoría de los ordenamientos jurídicos. En la actualidad, los motivos por los que se realiza un préstamo o un trasplante vienen más determinados por la globalización y por la necesidad de alcanzar ciertos estándares normativos que ayuden una mejor relación entre los distintos sistemas jurídicos. Y ya no es tanto el prestigio o la fuerza lo que motiva la recepción normativa, sino alienarse con ciertos valores, como los Derechos Humanos o el medio ambiente, o con estándares para una mejor relación y comunicación jurídica o económica. Son motivaciones que interesan a ambas partes, al ordenamiento jurídico que sirve como modelo y al receptor, porque buscan 
un mayor entendimiento en una época en la que la globalización impone un alto grado de relación e influencia mutua. Aquí ya la teoría de los formantes legales de Sacco no llega ya a satisfacer tanto, porque la fuerza o el prestigio dejan de ser ya tan determinantes, pero sí ayudaron a entender que, fuera por uno u otro, la introducción de una norma ajena produce variaciones entre los formantes y reconfigura esos espacios de disociación a los que aludimos más arriba.

En la actualidad, sin la importancia difusionista de la fuerza o el prestigio, más que nada porque son variables de análisis que se concentran más sobre la capacidad influenciadora del ordenamiento jurídico emisor y su posición hegemónica, la teoría de los trasplantes jurídicos comienza a tomar una mejor posición en la explicación estructuralista de la circulación normativa. Los trasplantes legales de Watson, al igual que los formantes de Sacco, tratan de demonstrar también que la principal causa de innovación o transformación jurídica se realiza a través del préstamo, pero esta vez con una mayor consideración del papel del receptor en la explicación del fenómeno. También aquí el prestigio juega un papel determinante, aunque en realidad de una manera indirecta, ya que los modelos jurídicos son seleccionados por los operadores jurídicos para su imitación y trasplante al ordenamiento jurídico imitador.

Como ya fuimos viendo más arriba, Watson utilizó la metáfora del trasplante para demostrar que la mayoría de los sistemas jurídicos actuales bebían de la destreza jurídica de los jurisconsultos romanos, pero también que esa circunstancia se debió a la percepción que sobre el derecho romano tenían los operadores jurídicos o lawmakers. Es decir, para Watson el prestigio del derecho romano no se adquirió desde una postura hegemónica, como un hecho objetivo derivado de la fuerza del Imperio romano en una época determinada que haya perdurado hasta la actualidad, sino que fue debido, principalmente, a la valoración que le dieron los operadores jurídicos posteriores, ya fuera por su calidad, por su accesibilidad o simplemente por su compatibilidad para regular un contexto social determinado. La base, pues, de la explicación estructuralista de Watson otorga a los agentes jurídicos o lawmakers un papel fundamental en la elaboración de la cultura jurídica de una determinada sociedad (Watson, 1995, p. 469), contraviniendo con ello la concepción predominante que por entonces consideraba que el derecho era una producción exclusiva de un contexto social y cultural concreto. Y la diferencia, por tanto, con la teoría de los formantes, es que los motivos por los cuales se produce un trasplante no se deben a la fuerza o prestigio de un ordenamiento jurídico determinado que provocan la imposición de un modelo, sino a la voluntad y actividad consciente de aquellos operadores jurídicos que ven en el préstamo una necesidad para lograr una trasformación jurídica concreta (Mousourakis, 2006, p. 60).

Frente a la imposición, por tanto, del modelo de los formantes de Sacco, la explicación estructuralista de Watson describe mediante los trasplantes una visión determinista, en el sentido de que son los agentes jurídicos los operadores del cambio y de la razón por la cual se produce una circulación normativa entre distintos ordenamientos jurídicos: es determinista en tanto que unos recursos jurídicos disponibles son utilizados por los operadores jurídicos para transformar su propio derecho. Eso sí, con un matiz adaptado a las influencias actuales: esos recursos jurídicos no están ahí de una manera espontánea, y su conocimiento y disponibilidad dependerá en mayor o menor medida del grado de influencia que hayan logrado conseguir para convertirse en un sistema jurídico de referencia, es decir, del prestigio que se haya logrado labrar. Tal puede ser el caso, por ejemplo, de la influencia de los ordenamientos jurídicos occidentales o, más en concreto, del modelo jurídico anglosajón en las relaciones comerciales, o la influencia recíproca que se está dando entre todos los ordenamientos jurídicos de la Unión Europea 
(Örücü, 2000). Puede haber, en definitiva, algunas influencias externas en la voluntad de los operadores jurídicos a la hora de elegir unos determinados recursos jurídico u otros, por lo que no siempre podremos afirmar una independencia total de su voluntad, lo que no quiere decir que esté viciada.

Por otro lado, con la perspectiva funcionalista también los iuscomparativistas tratan de evitar establecer una relación determinista entre el derecho y la cultura o la antropología, pero de una manera distinta. La principal aportación de los funcionalistas al derecho comparado radica sobre todo en la reducción del ámbito de análisis de los elementos jurídicos a comparar: en primer lugar, cuando reducen el análisis únicamente hacia los hechos factuales y no a los conceptuales. Esto es, que a los funcionalistas lo único que les interesa son las soluciones técnico-jurídicas que un determinado ordenamiento jurídico haya adoptado para resolver una situación concreta, evitando introducir en el análisis cualquier consideración moral o ideológica (Zweigert \& Kötz, 1998). La utilidad de esta observación más aséptica permite a los funcionalistas encontrar similitudes prácticas entre los diferentes ordenamientos jurídicos, aunque las soluciones técnico-jurídicas sean completamente diferentes. De este modo, de entre todos los sistemas jurídicos pueden llegar a identificar soluciones muy parecidas o idénticas para los mismos problemas, y todo ello a pesar de las notables diferencias históricas, sociales o doctrinales que entre ellos se puedan encontrar. Con esta postura metodológica, los funcionalistas consiguen alienarse con las propuestas neoinstitucionalistas, al conseguir proyectar el enfoque de su análisis en el papel que las diferentes instituciones pueden jugar en el funcionamiento del derecho, y no sobre los condicionantes morales o doctrinales. Se trata, en definitiva, de encontrar una equivalencia funcional entre las diferentes soluciones técnico-jurídicas de los diferentes ordenamientos jurídicos.

Con ello consiguen, en segundo lugar, elaborar una concepción apolítica del derecho, puesto que, al dejar atrás todas las consideraciones morales o ideológicas, el sistema jurídico analizado consigue adquirir una presunción de neutralidad que transforma todos sus elementos normativos en cuestiones de carácter meramente técnico. De esta manera, para cualquier análisis se logra visualizar al derecho como un sistema de engranaje en el que sus diferentes elementos responden, desde un punto de vista jurídico, únicamente a consideraciones de carácter mecánico. Es, en definitiva, una manera de establecer cierta racionalidad en los sistemas jurídicos al desprenderles de sus aspectos más esencialistas. Según los funcionalistas, sobre cualquier derecho se pueden aislar todos sus elementos técnico-jurídicos y establecer una presunción de similitud entre ellos (Zweigert \& Kötz, 1998, p. 36), a excepción de aquellas áreas jurídicas con una profunda huella cultural o ideológica, como pueda ser el derecho de familia, donde pueden existir ciertos valores sociales muy arraigados en los que cualquier intento de análisis racional puede llevar hacia una aporía, puesto que el juicio del evaluador puede estar condicionado por imperativos morales (Somma, 2015, p. 160). Con este distanciamiento, los funcionalistas consiguen imponer, de alguna manera, cierta retórica racionalista por la cual, por un lado, consiguen crear discusiones desapasionadas sobre los elementos técnico-jurídicos del derecho desde una perspectiva comparada, pero a la vez, por otro, establecen también condicionantes valorativos sobre todos aquellos sistemas jurídicos que, desde su perspectiva, no puedan separar sus elementos más esencialistas para su análisis. Con ello provocan, de una manera indirecta, una jerarquización entre sistemas jurídicos racionales $\mathrm{y}$, vamos a decir, culturalmente condicionados, que necesitarían una transformación profunda hacia una mayor racionalización para acceder a un cierto estatus que les permitiera codearse a un nivel global con el resto de los sistemas jurídicos. 
Alguna de las propuestas funcionalistas ha aparecido como contrapunto crítico de la teoría de los trasplantes jurídicos de Watson. Una de las más singulares es la propuesta de Gunther Teubner, quien retuerce la metáfora de Watson para renombrarla como irritantes legales (Teubner, 1998). Esta metáfora particular, más que configurarse como una crítica total, trata en realidad de complementar o redefinir algunos de los perfiles que más dudas pudieran haber generado en la elaboración del concepto de trasplante jurídico. Los irritantes jurídicos, expresión que toma Teubner de la teoría de sistemas de la cual es experto y que hace referencia al contacto no estructural entre sistemas jurídicos, pretenden exponer las posibles transformaciones que se pueden dar en el ordenamiento jurídico receptor al trasplantarle una norma ajena. Según Teubner, el principal defecto de la teoría de Watson es que su teorización sobre la circulación normativa únicamente intenta dar una explicación descriptiva sobre el fenómeno de los préstamos jurídicos desde el punto de vista del receptor, pero sin dar cuenta de las consecuencias sustantivas que se puedan generar en el mismo tras el trasplante. Los irritantes jurídicos, por tanto, tratan de complementar la metáfora del trasplante para explicar las transformaciones jurídicas que irremediablemente sufren los sistemas jurídicos receptores al tomar prestada una norma. Con ello, Teubner intenta explicar que en cualquier trasplante jurídico la norma no viaja íntegramente de un sistema a otro, sino que se producen cambios y transformaciones inevitables en la norma prestada para que pueda tener cabida en el ordenamiento jurídico receptor, pero también en éste, al tener que adaptar su estructura a la nueva norma trasplantada. Para Teubner no hay, en definitiva, ninguna posibilidad de que se produzca un trasplante íntegro de la norma, ya que en el proceso se producen mutaciones jurídicas, por lo que tampoco se llega a producir una equivalencia total entre la norma transferida y la trasplantada. En estos casos, por tanto, el trasplante jurídico provoca mediante su irritación un proceso de reconversión del sistema jurídico receptor hacia, a veces, situaciones jurídicas inesperadas (Teubner, 1998, p. 12), dando lugar a un acoplamiento del ordenamiento jurídico que, finalmente, aúna elementos de la norma transferida con la naturaleza propia del sistema jurídico, lo que de alguna manera demuestra la conexión actual de los múltiples sistemas jurídicos entre sí y de la evolución del derecho hacia situaciones de pluralismo jurídico e interlegalidad (Sousa Santos, 2002).

Esta imposibilidad, por tanto, de establecer una equivalencia total de la norma trasplantada entre su función en el sistema jurídico emisor y su adaptación final en el receptor, y que Teubner lo encuentra determinante y necesario señalar como fenómeno ineludible en la circulación normativa, Pierre Legrand, por otra parte, lo utiliza para negar la posibilidad absoluta de los trasplantes jurídicos (Legrand, 1997). Con este enconado nihilismo, Legrand considera que todo sistema jurídico está atravesado por una dimensión cultural determinada, lo que haría imposible trasplantar normas de culturas jurídicas distintas o incompatibles, ya que todo sistema jurídico posee su propio mundo de significados (Legrand, 1997, p. 114). Ninguna norma podría ser trasplantada de un ordenamiento jurídico a otro porque el sentido que pueda tener en uno puede ser completamente distinto al que alcance en el otro. $Y$ esto es así porque, al atravesar las fronteras jurídicas, en el trasplante jurídico cualquier norma sufre una transformación que afecta a su naturaleza primigenia, ya que la interpretación que ha tenido en uno será completamente diferente en el otro. La conclusión, por tanto, que se obtiene de esta imposibilidad es que las culturas jurídicas son desgraciadamente inconmensurables, con lo que cualquier regla jurídica sería ininteligible fuera de su contexto legal o cultural.

Esta crítica de Legrand, que podría interpretarse como una resignación ante las diferencias constitutivas de las culturas jurídicas y la imposibilidad de cualquier 
ejercicio comparativo que busque hallar puntos de encuentro, en realidad encierra una defensa férrea de la idiosincrasia de las mismas. Con esta inconmensurabilidad, lo que Legrand se propone, es defender la particularidad de cada una de las culturas jurídicas existentes, frente a un posible proceso de homogenización que podría estar ocurriendo con la globalización. Según entiende, la utilización de una terminología aglutinadora en algunos discursos dominantes sobre la racionalización del derecho en un mundo global, escondería, en realidad, una agenda claramente ideológica en favor de culturas jurídicas afines a un modelo de capitalismo (Legrand, 2006). Los trasplantes jurídicos, por tanto, sólo serían un mecanismo de homogenización forzada para determinados sistemas jurídicos que quisieran relacionarse a un nivel global con otros ordenamientos jurídicos con una interpretación normativa que, en realidad, habrían alcanzado una condición hegemónica y estarían intentando imponerse. En definitiva, los trasplantes jurídicos no serían posibles, ya que estarían eliminando del análisis comparativo la variable del poder, pero sí lo podría seguir siendo el uso de una disciplina comparativa en derecho, aunque únicamente para mostrar una dialéctica inevitable entre las diferentes culturas jurídicas (Legrand, 2006a).

\section{Pluralismo jurídico y dimensión étnica de los trasplantes jurídicos}

Con los trasplantes jurídicos, Watson inauguró toda una discusión comparativa sobre la circulación normativa y la influencia recíproca entre los diferentes sistemas jurídicos. Pero hoy en día, los debates en torno al préstamo y trasplante de normas jurídicas han quedado ya muy determinados por el contexto de la globalización, el desarrollo económico o la democratización de las sociedades, para poder llegar a unos estándares comunes que legitimen a los Estados a entablar relaciones de confianza entre sí. Esta nueva situación comparativa ha fomentado la aparición, ya a partir de la última década del siglo pasado, de dos nuevos enfoques para el estudio de los trasplantes jurídicos (Miller, 2003): uno sobre el crecimiento y desarrollo de proyectos promovidos por grupos de Estados y fundaciones para la promoción de reformas jurídicas para la democratización y desarrollo económico; y otro sobre el creciente impacto del derecho internacional público en la promoción internacional de normas de derecho interno que, desde el consenso entre los diferentes Estados, se convierten en reglas trasnacionales. Yo añadiría una tercera, algo que tiene que ver con el contenido de este último epígrafe: la importancia creciente, en esta ocasión, del derecho internacional privado en el reconocimiento de la diversidad cultural y, por tanto, jurídica de los Estados modernos con la llegada de la inmigración y el auge de las relaciones trasnacionales con la globalización.

El contexto internacional y actual de los Estados modernos ha modificado, por tanto, la percepción de los motivos y adecuaciones de los trasplantes jurídicos. Como hemos repetido ya varias veces, a un nivel macro se impone la adopción de reglas estandarizadas que, de forma consensuada por todos, acaban siendo trasplantadas a los ordenamientos jurídicos de los Estados para mejorar el entendimiento mutuo y las relaciones entre los mismos, a fin de dotar al nuevo sistema de relaciones de cierta previsibilidad. Entre las principales preocupaciones están las integraciones regionales de los Estados en grandes entidades supranacionales como la Unión Europea; el entendimiento entre los dos grandes modelos jurídicos, el continental y el common-law; o el seguimiento de los sistemas jurídicos en desarrollo. Sobre todas estas cuestiones se han ido identificando canales de influencia jurídica mutua entre los diferentes ordenamientos jurídicos. Pero estos nuevos cauces de interacción jurídica ya no sólo se producen entre sistemas jurídicos entre sí, sino también entre sistemas jurídicos y contextos 
socioculturales, o entre sistemas jurídicos y las diferentes culturas jurídicas. Son, en definitiva, nuevas situaciones de interacción determinadas por la globalización, el multiculturalismo y la aparición del fenómeno del pluralismo jurídico (Örücü, 2000).

El problema de los trasplantes jurídicos en las primeras teorías de Watson, o de los préstamos en general en las primeras propuestas de los iuscomparativistas, fue que únicamente se configuraron para explicar o, más bien, describir el fenómeno por el cual se produce un trasvase normativo de un sistema jurídico a otro sin haber entrado a considerar, en cambio, el papel determinante de la cultura jurídica del país origen de la norma o la de su receptor, como tampoco las posibles consecuencias normativas de aceptar la inclusión de una norma jurídicamente ajena. $Y$ otra carencia también de estas teorías es que intentaban describir esta circulación normativa desde un punto de vista demasiado institucional o sistémico, solamente desde la mirada de los operadores jurídicos o mediante el análisis de las propias normas, sin entrar a considerar la fuerza de las subjetividades de los distintos sujetos e individuos que pueden haber empujado a la adopción de ese préstamo o trasplante. Es decir, por un lado, tenemos, en primer lugar, teorías sobre los préstamos y trasplantes jurídicos que no tienen en cuenta los resultados de la circulación normativa ni tampoco el cambio de motivaciones para adoptar mediante el trasplante normas de otros sistemas jurídicos, ahora más conectadas con necesidades de cooperación y coordinación entre Estados. Pero, por otro, tampoco tenemos, en segundo lugar, ningún análisis sobre las consecuencias jurídicas y normativas de la adopción de una norma mediante el trasplante, de la posible configuración mixta de la jurisdicción del Estado receptor, de la estandarización de algunas de sus áreas jurídicas con una consecuente pérdida de la identidad jurídica o de, en definitiva, cualquier consecuencia que debiera afectar la futura armonización del ordenamiento jurídico transformado mediante el trasplante jurídico. Todo ello, termina afectando a la manera de abordar las implicaciones futuras del sistema jurídico con respecto a una nueva realidad social y jurídica, una en la que los trasplantes jurídicos pueden llegar a ser una constatación de la superposición de los ordenamientos jurídicos entre sí y la de su permeabilidad ante los nuevos factores de la globalización, la inmigración o las nuevas relaciones trasfronterizas desde un punto de vista jurídico. El énfasis, por tanto, de este nuevo análisis de los trasplantes jurídicos debe concentrarse ahora en evaluar los posibles conflictos por la adopción de normas de otros sistemas jurídicos, la posible promoción de cambios jurídicos bottom-up por medio de la acción de sujetos particulares o, finalmente, la difícil resolución de la compatibilidad de normas trasplantadas con áreas jurídicas cultural e ideológicamente acotadas que llevan a aporías de difícil resolución. Todo ello teniendo en cuenta, de un modo particular, los conflictos irremediables del aumento de la diversidad cultural de nuestras sociedades y la consecuente importación de nuevas perspectivas jurídicas que van dando forma, aún de un modo descriptivo, a una realidad protagonizada por el pluralismo jurídico.

Durante los últimos años, el pluralismo jurídico ha servido para establecer una importante perspectiva crítica frente a los incondicionales del centralismo o del positivismo jurídico. Con la globalización, la mayoría de los Estados han visto amenazado su monopolio sobre la producción normativa, pero siguen resistiéndose a reconocer una situación jurídico plural que les pudiera relegar a un plano no tan preponderante como antaño. Los defensores del pluralismo jurídico, en cambio, defienden la asunción 0 , al menos, el reconocimiento, de la complejidad que ha alcanzado el espacio jurídico en cualquier nivel y de la necesidad de construir nuevas perspectivas que aboguen por dar cabida a una realidad jurídica plural que amplíe las bases conceptuales del derecho más allá de la visión monista predominante. Dentro de esta nueva perspectiva, los trasplantes jurídicos han servido también para algunas propuestas como indicadores de una existencia 
jurídica plural. De este modo, algunos autores mantienen que la constatación del pluralismo jurídico puede demostrase también a través de la identificación de los trasplantes jurídicos, señalando, de esta manera, la forma que tienen los diferentes sistemas jurídicos de entenderse entre sí aceptando la naturaleza jurídica de cada uno de ellos mediante la incorporación de sus normas. En muchas propuestas actuales, por tanto, los trasplantes jurídicos sirven también como mecanismo argumental para reforzar el énfasis en la constatación de la existencia del pluralismo jurídico mediante la identificación concreta de las normas trasplantadas.

Hasta finales del siglo pasado, la metáfora del trasplante jurídico daba cuenta de una manera potentemente descriptiva del fenómeno por el cual una norma de un sistema jurídico es adoptada por otro. Pero las carencias para la definición de sus consecuencias impulsaron nuevas propuestas teóricas en torno a los trasplantes, menos desapasionadas que las anteriores perspectivas y ahora teniendo en cuenta, esta vez sí, la variable cultural. De hecho, gran parte de la revitalización del trasplante jurídico como metáfora se debió a las propuestas teóricas de autores como Masaji Chiba, quien empezó a utilizar el término para completar sus teorías sobre el pluralismo jurídico. Chiba comenzó a utilizar el término trasplante para definirlo como el fenómeno por el cual una norma de un pueblo se traslada a la cultura jurídica de otro (Chiba, 1989, p. 179). Es quien, por tanto, introdujo el elemento cultural en la ecuación comparativa del análisis del mecanismo del trasplante jurídico. Chiba quería establecer con ello una relación causal entre el trasplante de normas y el pluralismo jurídico, al hablar de la circulación de normas entre los distintos países gracias al movimiento migratorio de individuos portadores de diferentes postulados legales. La teoría del pluralismo jurídico de Chiba está atravesada por una perspectiva subjetiva muy reveladora en cuanto a función que desempeña el sujeto en la configuración de una situación jurídica plural. Para Chiba, el pluralismo jurídico contiene una dimensión subjetiva que explica la transformación de los espacios jurídicos allí donde un portador de distintas cosmovisiones jurídicas, o de diferentes postulados legales, pretende hacer valer una posición jurídica propia (Chiba, 1998, p. 238 y ss.). Con ello quiere dar cuenta Chiba de la importancia que adquiere el sujeto en la provocación de una situación jurídica plural, quien no adopta una postura meramente pasiva, sino que se convierte en agente o precursor legal, al elegir entre los diferentes sistemas jurídicos que le atraviesan, lo cual le sirve para reafirmar su elección jurídica como cultural o étnicamente motivada (Chiba, 1998, p. 239). Esta posibilidad, una en la que pueda darse una situación jurídica plural y pueda producirse entonces un trasplante jurídico, no evita en absoluto la posibilidad de conflicto. Para Chiba, a diferencia de lo que proponen otras teorías sociológicas, que ven en el conflicto una amenaza al orden social, la posibilidad de conflicto jurídico y normativo debe tomarse como una oportunidad para el cambio y la adaptación del sistema jurídico receptor al nuevo contexto social que le rodea (Chiba, 1998, p. 237).

El conflicto jurídico, por tanto, no es una amenaza ni una condena contra el orden social, sino que es una oportunidad para el cambio y adaptación jurídica del derecho. Y la manera de resolver el conflicto en estas situaciones le ha sido encomendada tradicionalmente a los órganos jurisdiccionales. Para este nuevo enfoque de los trasplantes jurídicos étnicamente condicionados, la utilización del derecho internacional privado ha llegado a ser uno de los principales mecanismos para la resolución de los conflictos que han podido surgir en el encuentro de normas pertenecientes a culturas jurídicas distintas. Mediante el derecho internacional privado y sus normas de conflicto, es decir, los mecanismos por los que se decide qué sistema jurídico hay que aplicar, los jueces y tribunales han llegado a trasplantar normas de otros sistemas jurídicos únicamente para resolver cuestiones de justicia sustantiva. A diferencia de las causas y motivos de los trasplantes jurídicos de las 
primeras teorías, en las que la fuerza o prestigio jugaban un papel determinante, desde la perspectiva del derecho internacional privado la motivación para la adopción de una norma ajena se sustenta, sobre todo, en el reconocimiento: el reconocimiento, por un lado, de una cultura jurídica particular y el reconocimiento, por otro, de una situación jurídica particular. La confluencia de ambas da como resultado la adopción de una decisión sustantivamente motivada por la cual los jueces y tribunales deciden resolver posibles aporías teniendo en cuenta, no la incompatibilidad de una norma y la incongruencia de su reconocimiento, si no la posible indefensión de algunos individuos por una interpretación demasiado estricta en la que no exista un esfuerzo por confluir la pertenencia cultural con una necesidad jurídica particular.

Sobre estos esfuerzos interpretativos y estas confluencias de los jueces y tribunales, muchos estudios actuales sobre la adopción de normas culturalmente ajenas han recuperado la metáfora del trasplante jurídico para señalar esos pequeños acoples de los sistemas jurídicos receptores (Fournier, 2010). En concreto, Fournier ha realizado un extenso estudio del reconocimiento de la figura de la dote islámica o mahr en diversos países occidentales como Estados Unidos, Canadá, Francia o Alemania. Con su estudio, Fournier ha querido analizar también los mecanismos de rechazo o reconocimiento de la figura islámica, extrapolables también a otras muchas parecidas, que utilizan los tribunales, quienes, según el país o la época de la resolución, adoptan perfiles más conservadores o progresistas. Algo que también se da en el entorno jurisdiccional español (Backenköhler Casajús, 2017). Son, en definitiva, nuevas formas de un reconocimiento normativo particular que toman como referencia descriptiva la metáfora del trasplante jurídico para, ya de una manera prescriptiva, jugar con las posibilidades teóricas y normativas que supone el encuentro entre culturas jurídicas diferentes y el establecimiento de una situación de pluralismo jurídico.

\section{Conclusiones}

Los trasplantes jurídicos son una poderosa metáfora. Estos tuvieron un papel relevante en la revitalización de las teorías difusionistas sobre la circulación normativa y el préstamo jurídico a partir de la década de los setenta con la obra de Alan Watson. Fuimos viendo que uno de los principales motivos para su configuración fue para justificar el origen común de la mayoría de los sistemas jurídicos de los países occidentales, pero, sobre todo, para desmitificar también el paralelismo natural que la sociología jurídica imponía hasta el momento entre el derecho y la sociedad.

Con el tiempo, y también con las discusiones teóricas sobre los distintos enfoques proyectados sobre el fenómeno del préstamo y los trasplantes jurídicos, el concepto ha ido evolucionado adaptando su contenido al nuevo contexto social, sobre todo con la importancia de la globalización. En los últimos años, el trasplante jurídico ha obtenido una revitalización importante sobre todo desde las teorías acerca del pluralismo jurídico. Aquí la novedad de su importancia se ha ido estableciendo en la consecuencia natural de las trasposiciones normativas entre los diferentes sistemas jurídicos, resultado también de un espacio jurídico atravesado por múltiples afiliaciones étnicas. En la actualidad, la figura del trasplante jurídico nos sigue sirviendo como metáfora descriptiva de ese proceso de adopción de una norma jurídicamente ajena, pero también de las posibles consecuencias de su incorporación $y$, sobre todo, de los futuros conflictos jurídicos a los que 
irremediablemente deberán enfrentarse los ordenamientos jurídicos para su mejor adaptación a la nueva realidad social que quedará por venir.

\section{Bibliografía}

Arminjon, P., Nolde, B. B., \& Wolff, M. (1950). Traité de Droit Comparé. Vol. 1. París, Francia: Librairie Générale de droit et de jurisprudence.

Backenköhler Casajús, C. J. (2017). Multiculturalismo y pluralismo jurídico de base religiosa: el derecho islámico en España. Revista CIDOB d'afers internacionals, 115, pp.119-139.

Chiba, M. (1989). Legal Pluralism: Toward a General Theory Through Japanese Legal Culture. Tokyo, Japón: Tokai University Press.

Chiba, M. (1998). Other Phases of Legal Pluralism in the Contemporary World. Ratio Juris, 11(3), pp. 228-245.

Fournier, P. (2010). Muslim marriage in western courts: Lost in transplantation. Farnham, Inglaterra: Ashgate Publishing Company.

Langer, M. (2004). From legal transplants to legal translations: The globalization of plea bargaining and the Americanization thesis in criminal procedure. Harvard International Law Journal, 45(1), pp. 1-64.

Legrand, P. (1997). The Impossibility of 'Legal Transplants'. Maastricht Journal of European and Comparative Law, 4(2), pp. 111-124.

Legrand, P. (2006). On the Singularity of Law. Harvard International Law Journal, 47(2), pp. 517-530.

Legrand, P. (2006a). Comparative Legal Studies and the Matter of Authenticity. Journal of Comparative Law, 1(2), pp. 365-460.

Luhmann, N. (2016). El enfoque sociológico de la teoría y práctica del Derecho. Anales de la Cátedra Francisco Suárez, 50, pp. 185-199.

Merryman, J. H. (2008). La tradición jurídica romano-canónica. México: Fondo de Cultura Económica.

Miller, J. M. (2003). A Typology of Legal Transplants: Using Sociology, Legal History and Argentine Examples to Explain the Transplant Proces. The American Journal of Comparative Law, 51(4), pp. 839-886.

Mousourakis, G. (2006). Towards a Comparative Theory of Legal Change. Kansai University Review of Law and Politics, 27, pp. 53-68.

Mousourakis, G. (2010). Transplanting Legal Models across Culturally Diverse Societies. A Comparative Law Perspective. Osaka University Law Review, 57, pp. 87-106.

Örücü, E. (2000). Critical Comparative Law: Considering Paradoxes for Legal Systems in Transition. EJCL. Netherlands Comparative Law Association, 4(1). Recuperado de https://www.ejcl.org//41/art41-1.html

Papagianni, K. (2005). Transitional Politics in Afghanistan and Iraq: Inclusion, Consultation, and Public Participation. Development in Practice, 15(6), pp. 747759.

Sacco, R. (1991). Legal Formants: A Dynamic Approach to Comparative Law (Installment I of II). The American Journal of Comparative Law, 39(1), pp.1-34.

Sacco, R. (1991a). Legal Formants: a Dynamic Approach to Comparative Law (Installment II of II). The American Journal of Comparative Law, 39(2), pp. 343401.

Shah, P. (2005). Legal Pluralism in Conflict: coping with cultural diversity in law. Londres, Inglaterra: Glass House Press.

Somma, A. (2015). Introducción al derecho comparado. Getafe, España: Universidad Carlos III de Madrid. 
Sousa Santos, B. d. (2002). Towards a New Legal Common Sense: Law, Globalization, and Emancipation. 2nd Edition. Londres, Inglaterra: Butterworths.

Teubner, G. (1998). Legal Irritants: Good Faith in British Law or How Unifying Law Ends Up in New Divergencies. The Modern Law Review, 61(1), pp.11-32.

Watson, A. (1993). Legal transplants: An approach to comparative law. Athens, Estados Unidos: University of Georgia Press.

Watson, A. (1995). From legal Transplants to Legal Formants. The American Journal of Comparative Law, 43(5), pp. 469-476.

Watson, A. (2001). Society And Legal Change (2nd Edition). Philadelphia, Estados Unidos: Temple University Press.

Zweigert, K., \& KÖTZ, H. (1998). An Introduction to Comparative Law. Oxford, Inglaterra: Clarendon Press. 